\title{
Aplicação foliar de produtos na redução da severidade da brusone do trigo
}

\author{
Maria Fernanda A. da Cruz ${ }^{1}$, Ana Paula C. Diniz², Fabrício A. Rodrigues² \& Everaldo Gonçalves de \\ Barros $^{1}$
}

${ }^{1}$ Departamento de Biologia Geral; ${ }^{2}$ Departamento de Fitopatologia, Universidade Federal de Viçosa, 36570-000, Viçosa, MG, Brasil

Autor para correspondência: Fabrício A. Rodrigues, e-mail: fabricio@ufv.br

\begin{abstract}
RESUMO
Este trabalho objetivou avaliar o potencial do ácido jasmônico (AJ), quitosana desacetilada (QUI), silicato de potássio (SP), acibenzolar-S-metil (ASM), Ethefon (ET) e fosfito de potássio (FP) na redução da severidade da brusone do trigo. O fungicida tebuconazole (TE) e a água destilada (AD) foram utilizados como tratamentos controle. Plantas das cultivares BR 23, BH 1146 e BRS 208 foram pulverizadas com AJ, QUI, SP, ASM, ET, FP, TE e AD 24 h antes da inoculação com Pyricularia grisea. Avaliou-se o período de incubação (PI), a severidade e o efeito fungitóxico dos produtos no crescimento micelial de $P$. grisea. Para o PI, não houve diferença significativa entre os fatores cultivares e tratamentos, mas para a severidade houve interação entre esses fatores. A menor severidade da brusone para a cultivar BR 23 ocorreu com a pulverização do TE, FP e ET, os quais não diferiram estatisticamente. Para BH 1146, os tratamentos AD, QUI e ASM não diferiram estatisticamente, mas diferiram dos demais tratamentos que apresentaram menor severidade. A aplicação do TE e do FP garantiram uma menor severidade da brusone para a cultivar BRS 208. O FP propiciou uma maior redução da severidade da brusone nos dois cultivares. Os menores valores para o crescimento micelial de $P$. grisea ocorreram com a adição de TE e SP no meio de cultura. Os resultados desse estudo apontam para o efeito promissor do FP e do ET na potencialização da resistência do trigo à brusone, a qual mostrou ser dependente do nível de resistência basal da cultivar de trigo.
\end{abstract}

Palavras-chave: Pyricularia grisea, Triticum aestivum, indução de resistência.

\begin{abstract}
Foliar application of products on the reduction of blast severity on wheat

This study aimed to determine the potencial of jasmonic acid (JA), deacetylated chitosan (DC), potassium silicate (PS), AcibenzolarS-Methyl (ASM), ethephon (ET), and potassium phosphate (PP) on the reduction of blast severity on wheat. The fungicide tebuconazole (TE) and distilled water (DA) were used as control treatments. Plants from the cultivars BR 23, BH 1146, and BRS 208 were sprayed with JA, DC, PS, ASM, ET, PP, TE, and DA $24 \mathrm{~h}$ before inoculation with Pyricularia grisea. The incubation period (IP), blast severity, and the effect of the treatments on mycelial growth of $P$. grisea were evaluated. For the IP, there was no significant difference among cultivars and also for the treatments, but there was interaction between these factors for severity. The lowest severity for BR 23 cultivar occurred with the spray of TE, PP, and ET, which were not significantly different among them. For BH 1146 cultivar, the treatments DA, DC, and ASM were not significantly different among them, but differed significantly from the other treatments to which were obtained the lowest severity. The spray of TE and PP gave the best reduction on severity for BRS 208 cultivar. The PP was the treatment that most reduced severity on the three cultivars tested. The lowest values for mycelial growth of $P$. grisea occurred upon the addition of TE and PS to the culture medium. The results of this study point to the promising effect of PP and ET in the potentiation of wheat resistance to blast disease, which showed to be dependent on the basal level of resistance of the cultivar.
\end{abstract}

Key words: Pyricularia grisea, Triticum aestivum, induced resistance.

A brusone do trigo, causada pelo fungo Pyricularia grisea (Cooke) Sacc. (teleomorfo: Magnaporthe grisea (Hebert) Barr.), foi diagnosticada primeiramente no Brasil em 1985 no estado do Paraná (Igarashi et al., 1986). Desde então, pesquisas em busca de cultivares resistentes a essa doença (Urashima et al., 2004; Arruda et al., 2005; Prestes et al., 2007, Cruz et al., 2009), marcadores moleculares para a caracterização de isolados do patógeno (Brondani et al., 2000; Cruz et al., 2010) e fungicidas eficientes (Goulart et al., 1993; Urashima \& Kato, 1994; Goulart et al., 1996) têm sido realizadas. Uma das maiores dificuldades em relação ao controle químico é a ineficiência dos fungicidas disponíveis no mercado devido a agressividade do patógeno ou quando o trigo é cultivado em regiões com condições climáticas favoráveis para a ocorrência de epidemias severas de brusone. Além disso, o custo de produção do trigo é encarecido pela aplicação de fungicidas, os quais também colocam em risco a saúde do aplicador e o meio ambiente.

Assim, o uso de indutores de resistência como uma estratégia de controle alternativo de doenças das plantas 
cultivadas desponta como uma prática que não afeta o meio ambiente devido à rápida degradação da molécula do indutor e também por proporcionar menor pressão de seleção na população do patógeno. Embora os indutores de resistência tenham sido utilizados na cultura do trigo para reduzir a intensidade de algumas doenças como a cárie (Mandal et al., 2006), o oídio (Chain et al., 2009) e a giberela (Makamar et al., 2010), nenhum trabalho investigou o potencial do uso de indutores no patossistema trigo-Pyricularia grisea. Assim, este trabalho objetivou determinar se a aplicação foliar de alguns produtos, alguns deles reconhecidos como indutores de resistência, aumentaria a resistência de três cultivares de trigo à brusone.

Sementes de trigo dos genótipos BR 23, BH 1146 e BRS 208 foram semeadas em vasos plásticos $(12 \mathrm{~cm}$ de diâmetro) contendo $300 \mathrm{~g}$ de substrato composto de casca de Pinnus bio-esterilizada, vermiculita, moinha de carvão vegetal, água e espuma fenólica. O experimento foi instalado em delineamento inteiramente casualizado (DIC) em esquema fatorial $3 \times 8$ com quatro repetições e cinco plantas por vaso. Os fatores estudados foram: três cultivares de trigo e oito produtos. Plantas no estádio 14 (Zadoks et al., 1974) foram pulverizadas $24 \mathrm{~h}$ antes da inoculação com $P$. grisea com soluções dos seguintes produtos: ácido jasmônico (AJ) (0,25 mM; Sigma-Aldrich), quitosana desacetilada (QUI) (1 g de QUI a 85\%/L; pH 5,8), silicato de potássio (SP) (20 g/L; Fertisil, PQ Silicas Brasil Ltda), Acibenzolar-S-Metil (ASM) $(0,3 \mathrm{~g} / \mathrm{L}$; Syngenta Proteção de Cultivos Ltda), Ethefon (ET) $(1,5 \mathrm{~mL} / \mathrm{L}$, SigmaAldrich) e fosfito de potássio (FP) $(6,4 \mathrm{~mL} / \mathrm{L}$; Agrichem). Plantas pulverizadas com o fungicida tebuconazole (TE) (10 $\mathrm{mL} / \mathrm{L}$ ) e água destilada (AD) serviram como tratamentos controle.

As plantas de trigo foram inoculadas com o isolado monospórico de $P$. grisea UFV-DFP-10, obtido do ráquis de espigas de trigo provenientes do campo experimental "Professor Diogo Alves de Mello" da UFV em 2008. O isolado foi preservado em papel de filtro a $-80^{\circ} \mathrm{C}$. Pedaços de papel de filtro foram transferidos para placas de Petri contendo meio de aveia-ágar. As placas de Petri foram transferidas para câmara de crescimento com temperatura de $25^{\circ} \mathrm{C}$ por 10 dias até a produção abundante de conídios. Os conídios foram removidos de cada placa com o auxílio de um pincel de cerdas macias e água destilada contendo gelatina $(10 \mathrm{~g} / \mathrm{L})$ e espalhante adesivo Tween 80 . As plantas foram inoculadas com uma suspensão de $2,5 \times$ $10^{4}$ conídios/mL utilizando-se atomizador "De Vilbiss" acoplado a um compressor de ar. Após a inoculação, as plantas foram transferidas para câmara de nevoeiro com as seguintes condições: $24 \mathrm{~h}$ no escuro, temperatura de $25^{\circ} \mathrm{C} \mathrm{e}$ nebulização por $3 \mathrm{~min}$ em intervalos de $30 \mathrm{~min}$. Decorrida as $24 \mathrm{~h}, \mathrm{o}$ fotoperíodo foi ajustado para $12 \mathrm{~h} \mathrm{luz} / 12 \mathrm{~h}$ escuro e nebulização para 1 min a cada $30 \mathrm{~min}$ com temperatura de $26 \pm 2^{\circ} \mathrm{C}$. Avaliou-se na folha A2 (Haun, 1973) de cada planta, o período de incubação (PI) a partir das 24 h após a inoculação e a severidade da brusone utilizando-se uma escala com valores de severidade variando de 0 a $100 \%$ (IRRI, 1996) aos 7 dias após a inoculação.

Para avaliar o efeito dos produtos no crescimento micelial de $P$. grisea, esses foram adicionados ao meio de cultura batata-dextrose-ágar (BDA) nas mesmas concentrações utilizadas para a pulverização das plantas. Um disco de BDA ( 9 mm de diâmetro) contendo micélio de $P$. grisea foi transferido para o centro de cada placa de Petri e o diâmetro da colônia, em mm, foi medido após 72 horas utilizando-se paquímetro digital. O experimento foi instalado em DIC com sete repetições. Cada repetição foi constituída por uma placa de Petri.

Os dados das variáveis PI, severidade e crescimento micelial de $P$. grisea foram submetidos à análise de variância e as médias comparadas pelo teste de Tukey ao nível de $5 \%$ de probabilidade, utilizando-se o software SAS (SAS Institute, Inc., Cary, NC).

Para o PI, o qual variou de 3,2 a 3,6 dias, não houve diferença significativa $(P=0,05)$ para os fatores cultivares e produtos, bem como para a interação desses fatores. Para a severidade da brusone, houve diferença significativa $(P=0,001)$ para os fatores cultivares, produtos e para a interação desses fatores. Não houve diferença significativa $(P=0,05)$ entre as três cultivares para os tratamentos água destilada (controle) e ASM (Tabela 1). Para os tratamentos $\mathrm{AJ}$ e SP, não houve diferença significativa $(P=0,05)$ entre as cultivares BR 23 e BH 1146, porém essas diferiram significativamente da cultivar BRS 208 por apresentarem os menores valores de severidade (Tabela 1). Não houve diferença significativa $(P=0,05)$ entre as cultivares BR 23

TABELA 1 - Severidade da brusone nas folhas das plantas de três cultivares de trigo pulverizadas com vários produtos visando indução de resistência

\begin{tabular}{ccccccccc}
\hline \hline \multirow{2}{*}{ Cultivares } & \multicolumn{9}{c}{ Produtos $^{1}$} \\
\cline { 2 - 8 } & AD & QUI & AJ & SP & ASM & TE & FP & ET \\
\hline BR 23 & $49,6 \mathrm{Aa}$ & $41,7 \mathrm{Bab}$ & $27,5 \mathrm{Bcd}$ & $29 \mathrm{Bcd}$ & $44,3 \mathrm{Aab}$ & $11,4 \mathrm{Be}$ & $17,9 \mathrm{Bde}$ & $21,6 \mathrm{Bde}$ \\
BH 1146 & $58,9 \mathrm{Aab}$ & $61,5 \mathrm{Aa}$ & $34,3 \mathrm{Bc}$ & $33,7 \mathrm{Bc}$ & $53,8 \mathrm{Aab}$ & $26,8 \mathrm{Ac}$ & $41,5 \mathrm{Abc}$ & $42 \mathrm{Abc}$ \\
BRS 208 & $57,3 \mathrm{Ab}$ & $42,1 \mathrm{Bcd}$ & $72,1 \mathrm{Aa}$ & $61 \mathrm{Aab}$ & $51,8 \mathrm{Abc}$ & $5,2 \mathrm{Bg}$ & $16,8 \mathrm{Bfg}$ & $25,1 \mathrm{Bef}$ \\
\hline
\end{tabular}

${ }^{1} \mathrm{AD}=$ água destilada; $\mathrm{QUI}=$ quitosana; $\mathrm{AJ}=$ ácido jasmônico; $\mathrm{SP}=$ silicato de potássio; $\mathrm{ASM}=$ Acibenzolar-S-Metil; TE = Tebuconazole; $\mathrm{FP}=$ fosfito de potássio e $\mathrm{ET}=$ ethefon.

Médias seguidas pela mesma letra, minúscula na linha e maiúscula na coluna, não diferiram estatisticamente pelo teste de Tukey ao nível de 5\% de probabilidade. 
e BRS 208 para os tratamentos QUI, TE, FP e ET, mas as duas cultivares diferiram significativamente $(P=0,001)$ da cultivar BRS 208, a qual apresentou os maiores valores de severidade (Tabela 1).

Para a cultivar BR 23, os menores valores de severidade foram obtidos, em ordem decrescente, com a aplicação do SP, AJ, ET, FP e TE, porém sem diferença significativa $(P=0,05)$ entre esses tratamentos (Tabela 1$)$. Entretanto, esses tratamentos foram significativamente diferentes $(P=0,001)$ dos tratamentos, em ordem decrescente, $\mathrm{AD}, \mathrm{ASM}$ e QUI, para os quais a severidade da brusone atingiu os maiores valores.

Para a cultivar BH 1146, os menores valores de severidade foram obtidos para as plantas pulverizadas com AJ, porém sem diferença significativa $(P=0,05)$ desse tratamento para os tratamentos SP, FP, ET e TE. Os tratamentos FP e ET não diferiram significativamente $(P=$ $0,05)$ da aplicação de AD (Tabela 1). Plantas da cultivar BRS 208 apresentaram os menores valores de severidade da brusone quando pulverizadas com o TE, mas sem diferença significativa $(P=0,05)$ para o $\mathrm{FP}$, o qual foi estatisticamente igual ao tratamento ET. Já a maior severidade da brusone foi obtida nas plantas pulverizadas com AJ e SP (Tabela 1). Dentre os produtos testados, o FP foi o mais eficiente, reduzindo em 64 e $71 \%$, respectivamente, a severidade da brusone nas cultivares BR 23 e BRS 208.

Para o crescimento micelial de $P$. grisea, não houve diferença significativa $(P=0,05)$ do tratamento $\mathrm{AD}$ (controle) para os tratamentos AJ, ET, QUI, FP e ASM (Tabela 2). Não houve também diferença significativa $(P=0,05)$ entre os tratamentos SP e TE para os demais tratamentos. O ASM reduziu significativamente $(P=0,001)$ o crescimento micelial de $P$. grisea em comparação com o AJ (Tabela 2).

A resistência sistêmica induzida (RSI) confere uma proteção sistêmica da planta à infecção por uma ampla gama de patógenos requerendo para tal, uma molécula sinalizadora de baixo peso molecular, como o ácido salicílico, associado com a produção de proteínas relacionadas com a patogênese e com a participação dos hormônios AJ e ET (Reymond \& Farmer, 1998; Durrant \& Dong, 2004). De acordo com Dong (1998), o AJ e o ET estão envolvidos com a resistência induzida não específica (local) através de uma rota diferente do AS. Porém, uma comunicação entre as rotas parece ser comum para regular a expressão dos genes envolvidos nos mecanismos de defesa (Reymond \& Farmer, 1998).

$\mathrm{O}$ uso de potencializadores de resistência que ativam rotas de resistência na planta é realizado com a aplicação de inúmeros produtos, tanto de origem biótica quanto abiótica. Dentre esses últimos, pode-se destacar o uso do ASM, um homólogo do AS que é capaz de aumentar de forma rápida e efetiva a atividade de algumas enzimas envolvidas na rota dos fenilpropanóides em plantas de Vigna unguiculata (Latunde-Dada \& Lucas, 2001). O efeito positivo do ASM na redução da intensidade de doenças tem sido verificado em dicotiledôneas, porém, em monocotiledôneas como o arroz,
TABELA 2 - Efeito de produtos visando indução de resistência no crescimento micelial de Pyricularia grisea

\begin{tabular}{lc}
\hline \hline Tratamentos & Crescimento micelial (mm) \\
\hline Ácido jasmônico & $13,07 \mathrm{a}$ \\
Ethefon & $12,36 \mathrm{ab}$ \\
Quitosana & $11,21 \mathrm{ab}$ \\
Água destilada & $11,14 \mathrm{ab}$ \\
Fosfito de potássio & $10,50 \mathrm{ab}$ \\
Acibenzolar-S-Metil & $8,57 \mathrm{~b}$ \\
Silicato de potássio & $3,43 \mathrm{c}$ \\
Tebuconazole & $0,10 \mathrm{c}$
\end{tabular}

${ }^{1}$ Médias seguidas pela mesma letra não diferem estatisticamente pelo teste de Tukey ao nível de 5\% de probabilidade.

esse indutor não se mostrou eficiente, pois essa gramínea já possui uma alta concentração endógena de ácido salicílico e aumento nos níveis desse hormônio quando as plantas são infectadas por um patógeno não é observado (Kogel $\&$ Laugen, 2005). Porém, esses pesquisadores verificaram ativação de respostas de defesa nos patossistemas trigoBlumeria graminis f.sp. tritici, cevada-Blumeria graminis f.sp. hordei; arroz-P. grisea e milho-Peronosclerospora sorghi quando as plantas foram pulverizadas com AS. No presente experimento, o ASM não foi eficiente em reduzir a severidade da brusone nas cultivares BH 1146 e BR 23 (Tabela 1).

A aplicação de AJ nas plantas da cultivar BRS 208 aumentou significativamente a severidade da brusone em comparação com as plantas das cultivares BR 23 e BH 1145 (Tabela 1). Em comparação com o tratamento AD, a aplicação de AJ nas plantas da cultivar BRS 208 também aumentou a severidade da brusone (Tabela 1). Diferente da resposta encontrada neste experimento onde o AJ mostrouse ineficiente em reduzir a severidade da brusone do trigo, Mandal et al. (2006) verificaram que a aplicação exógena desse hormônio em cultivares de trigo antes da inoculação com Tilletia indica induziu a lignificação da parede celular. O metil-jasmonato nas concentrações de 20 e $30 \mathrm{mM}$ foi eficiente em reduzir a severidade da ferrugem do trigo quando aplicado aos 30 e 50 dias após o espigamento (Haggag \& Abd-El-Kareem, 2009).

De acordo com Liu et al. (2008), ocorreu um antagonismo entre o ASM e o AJ quando as plantas de pepino foram infectadas por Colletotrichum orbicule. Nesse caso, o ASM induziu resistência sistêmica local e também resistência sistêmica adquirida. O AJ induziu suscetibilidade local e induzida pela supressão do gene CHI2, o qual codifica para a produção de quitinase, enquanto o contrário foi verificado para as plantas pulverizadas com o ASM. No presente trabalho, tal antagonismo não foi verificado, pois tanto o ASM quanto o AJ proporcionaram redução na severidade da brusone nas três cultivares testadas.

O ET, promotor da síntese de etileno, também tem sido utilizado na redução do estresse biótico, servindo como um componente da sinalização do processo de indução de 
resistência. Contudo, a resposta desse indutor é dependente do patossistema e da época de aplicação. O uso do ET pode aumentar a severidade de uma doença ao favorecer o amadurecimento e a senescência de folhas e frutos. Em relação à época de aplicação do ET, observa-se que quando esse é aplicado antes da inoculação ocorre redução ou nenhum efeito no progresso da doença. Entretanto, quando as plantas são pulverizadas após a inoculação, o progresso da doença é promovido (Van Loon et al., 2006). No presente experimento, o ET mostrou-se eficiente em reduzir a severidade da brusone nas três cultivares testadas.

O uso de SP foi eficiente em reduzir os sintomas da ferrugem do cafeeiro e da soja, pois ao ser depositado e polimerizado sobre as folhas dificulta a penetração dos patógenos (Pereira et al., 2009; Rodrigues et al., 2009). Outro indutor utilizado em dicotiledôneas é a QUI que segundo Di Piero \& Garda (2008) reduziu a severidade da antracnose em feijoeiro em mais de $50 \%$. De acordo com El-Hadrami et al. (2010), a QUI aumentou a lignificação, a variação no fluxo de íons, a acidificação do citoplasma, a despolarização das membranas, a fosforilação de proteínas, a biossíntese de fitoalexinas e de ácido jasmônico, maior atividade de quitinases e $\beta$-1,3-glucanases e a geração de espécies reativas de oxigênio, porém essas funções foram dependentes do grau de desacetilação da QUI. Segundo esses autores, o sucesso na redução da intensidade da doença pelo uso da QUI depende do patossistema e da concentração e do grau de desacetilação. Rodríguez et al. (2007) associaram a capacidade da QUI em elicitar respostas de defesa do arroz à $P$. grisea com a concentração e ao grau de desacetilação. No presente estudo, a QUI não se mostrou eficiente em reduzir a severidade da brusone nas cultivares BR 23 e BH 1146.

O FP tem sido eficiente em reduzir a murcha causada por Verticillium dahliae em cacaueiro (Ribeiro Júnior et al., 2006). No presente estudo, o FP não apresentou efeito fungitóxico à $P$. grisea, mas foi capaz de reduzir a severidade da brusone. O uso de insumos contendo fosfito e silicatos é uma prática difundida entre os produtores, que conseguem tanto um efeito protetor contra patógenos, quanto um efeito de fertilizante. De acordo com Araújo et al. (2010), ocorre uma relação direta entre a acidez e formulação do FP com o crescimento micelial e a germinação de conídios de Colletotrichum gloeosporioides.

Os resultados desse estudo apontam para o efeito promissor do uso de produtos, a exemplo do FP e ET, na potencialização da resistência do trigo à brusone, porém o efeito parece ser dependente do nível de resistência basal da cultivar de trigo.

\section{AGRADECIMENTOS}

Ao Conselho Nacional de Desenvolvimento Científico e Tecnológico - CNPq, Coordenação de Aperfeiçoamento de Pessoal de Nível Superior - CAPES e Fundação de Amparo à Pesquisa do Estado de Minas Gerais
- FAPEMIG pelo financiamento parcial desse estudo. Ao $\mathrm{CNPq}$ pelas bolsas de Produtividade em Pesquisa aos professores F.A. Rodrigues e E.G. Barros. Às empresas Agrichem, PQ Silicas Brasil Ltda. e Syngenta Proteção de Cultivos Ltda. pelo fornecimento dos produtos fosfito de potássio, FertiSile Bion, respectivamente.

\section{REFERÊNCIAS BIBLIOGRÁFICAS}

Araújo L, Valdebenito-Sanhueza RM, Stadnik MJ (2010) Avaliação de formulações de fosfito de potássio sobre Colletotrichum gloeosporioides in vitro e no controle pós-infeccional da mancha foliar de Glomerella em macieira. Tropical Plant Pathology 35:5459.

Arruda MA, Bueno CRNC, Zamprogno KC, Lavorenti NA, Urashima AS (2005) Reação do trigo a Magnaporthe grisea nos diferentes estádios de desenvolvimento. Fitopatologia Brasileira 30:121-126.

Brondani C, Brondani RPV, Garrido L, Ferreira ME (2000) Development of microsatellite markers for genetic analysis of Pyricularia grisea. Genetics and Molecular Biology 23:753-762.

Chain F, Côté-Beaulieu C, Belzile F, Menzies JG, Bélanger RR (2009) A comprehensive transcriptomic analysis of the effect of silicon on wheat plants under control and pathogen stress conditions. Molecular Plant-Microbe Interactions 22:1322-1330.

Cruz MFA, Maciel JLN, Prestes AM, Bombonatto EAS, Pereira JF, Consoli L (2009) Caracterização genética e fenotípica de isolados de Pyricularia grisea do trigo. Tropical Plant Pathology 34:393-401.

Cruz MFA, Prestes AM, Maciel JLN, Scheeren PL (2010) Resistência parcial à brusone de genótipos de trigo comum e sintético nos estádios de planta jovem e de planta adulta. Tropical Plant Pathology 35:24-31.

Di Piero RM, Garda MV (2008). Quitosana reduz a severidade da antracnose e aumenta a atividade de glucanase em feijoeirocomum. Pesquisa Agropecuária Brasileira 43:1121-1128.

Dong X (1998) AS, JA, ethylene, and disease resistance in plants. Current Opinion in Plant Biology 1:316-323.

Durrant WE, Dong X (2004) Systemic acquired resistance. Annual Review of Phythopathology 42:185-209.

El Hadrami A, Adam LR, El Hadrami I, Daayf F (2010) Chitosan in plant protection. Marine Drugs 8:968-987.

Goulart ACP, Paiva FA (1993) Avaliação de fungicidas no controle da brusone "Pyricularia oryzae" do trigo (Triticum aestivum). Fitopatologia Brasileira 18:167-173.

Goulart ACP, Paiva FA, Melo Filho GA, Richetti A (1996) Efeito da época e do número de aplicações dos fungicidas tebuconazole e mancozeb no controle da brusone (Pyricularia grisea) do trigo; viabilidade técnica e econômica. Fitopatologia Brasileira 21:381387.

Haggag WM, Abd-El-Kareem F (2009) Methyl jasmonate stimulates polyamines biosynthesis and resistance against leaf rust in wheat plants. Archives of Phytopathology and Plant Protection 42:16-31.

Haun JR (1973) Visual quantification of wheat development. Agronomy Journal 65:116-119. 
Igarashi S, Utiamada CM, Igarashi LC, Kazuma AH, Lopes RS (1986) Pyricularia sp. em trigo. I. Ocorrência de Pyricularia sp. no estado do Paraná. In: $14^{\mathrm{a}}$ Reunião Nacional de Pesquisa de Trigo, Resumos... Londrina PR. IAPAR. p. 57.

International Rice Research Institute (1996) Standard Evaluation System for Rice, $4^{\text {th }}$ Ed. Manila Philippines. IRRI.

Kogel KH, Langen G (2005) Induced disease resistance and gene expression in cereals. Cellular Microbiology 7:1555-1564.

Latunde-Dada A, Lucas JA (2001) The plant defence activator acibenzolar-S-methyl primers cowpea (Vigna unguiculata (L.) Walp.) seedlings for rapid induction of resistance. Physiological and Molecular Plant Pathology 58:199-208.

Liu C, Ruan Y, Lin Z, Wei R, Peng Q, Guan C, Ishii H (2008) Antagonism between acibenzolar-S-methyl-induced systemic acquired resistance and jasmonic acid-induced systemic acquired susceptibility to Colletotrichum orbiculare infection in cucumber. Physiological and Molecular Plant Pathology 72:141-145.

Mandal KM, Pandey D, Purwar S, Singh US, Kumar A (2006) Influence of jasmonic acid as potential activator of induced resistance against Karnal bunt in developing spikes of wheat. Journal of Bioscience 31:607-616.

Makandar R, Nalam V, Chaturvedi R, Jeannotte R, Sparks AA, Shah J (2010) Involvement of salicylate and jasmonate signaling pathways in Arabidopsis interaction with Fusarium graminearum. Molecular Plant-Microbe Interactions 23:861:870.

Pereira SC, Rodrigues FA, Carré-Missio V, Oliveira MGA, Zambolim L (2009) Efeito da aplicação foliar de silício na resistência à ferrugem e na potencialização da atividade de enzimas de defesa em cafeeiro. Tropical Plant Pathology 34:223-230.

Prestes AM, Arendt PF, Fernandes JMC, Scheeren PL (2007) Resistance to Magnaporthe grisea among Brazilian wheat genotypes. In: Buck HT, Nisi JE, Salomón N. (Eds.) Wheat production in stressed environment. Dordrecht Netherlands. Springer. pp. 119-124.

Reymond P, Farmer EE (1998) Jasmonate and salicylate as global signals for defense gene expression. Current Opinion in Plant Biology 1:404-411.

Ribeiro Júnior PM, Resende MLV, Pereira RB, Cavalcanti FR, Amaral DR, Pádua MA (2006). Fosfito de potássio na indução de resistência a Verticillium dahliae Kleb. em mudas de cacaueiro (Theobroma cacao L.). Ciência Agrotécnica 30:629-636.

Rodrigues FA, Duarte HSS, Domiciano GP, Souza CA, Korndörfer GH, Zambolim L (2009). Foliar application of potassium silicate reduces the intensity of soybean rust. Australasian Plant Pathology 38:366-372.

Rodríguez AT, Ramírez MA, Cárdenas RM, Hernández NA, Velázquez MG, Bautista S (2007). Induction of defense response of Oryza sativa L. against Pyricularia grisea (Cooke) Sacc. by treating seeds with chitosan and hydrolyzed chitosan. Pesticide Biochemistry and Physiology 89:206-215.

Urashima A, Kato H (1994) Varietal resistance and chemical control of wheat blast fungus. Summa Phytopathologica 20:107112.

Urashima AS, Lavorenti NA, Goulart ACP, Mehta YR (2004) Resistance spectra of wheat cultivars and virulence diversity of Magnaporthe grisea isolates in Brazil. Fitopatologia Brasileira 29:511-518.

Van loon LC, Geraats BPJ, Linthorst HJM (2006) Ethylene as a modulator of disease resistance in plants. Trends in Plant Science 11:184-191.

Zadoks JC, Chang TT, Konzak CF (1974) A decimal code for the growth stages of cereals. Weed Research 14:415-421.

TPP 240 - Recebido 26 January 2011 - Aceito 28 December 2011 Editor de Seção: F. Murilo Zerbini 